\title{
Zinc-Catalyzed Multicomponent Reactions: Easy Access to Furyl- Substituted Cyclopropane and 1,2-Dioxolane Derivatives
}

\author{
Sergio Mata, ${ }^{[a]}$ Jesús González, ${ }^{[a]}$ Rubén Vicente, ${ }^{[a]}$ and Luis A. López ${ }^{\star[a]}$
}

Dedication ((optional))

\begin{abstract}
A convenient synthesis of cyclopropyl-substituted furan derivatives based on a zinc-catalyzed three-component coupling of 1,3-dicarbonylic compounds, 2-alkynals and alkenes is reported. A sequence consisting of initial Knoevenagel condensation, cyclization and final cyclopropanation reaction would account for the formation of the final products. In most cases this multicomponent process takes place in good yield, under mild reaction conditions and in the presence of a low catalyst loading. The efficient formation of 1,2dioxolane derivatives through zinc-promoted aerobic oxidation of some cyclopropane derivatives is also reported. The 1,2-dioxolane derivatives are also available through a four-component reaction.
\end{abstract}

\section{Introduction}

Nowadays, there is growing agreement within the scientific community on the need for more sustainable synthetic methodologies. In order to reach this general goal, some approaches have been established in the last few years. One of the most popular tactic entails the use of catalysts based on affordable metals as a replacement for those still widely-used based on precious metals, whose use exhibits several drawbacks such as limited availability, high price and toxicity that make them clearly far from optimal, mainly for large scale applications. ${ }^{[1]}$ On the other hand, the use of multicomponent reactions (MCRs) has also become particularly useful since these protocols offer clear advantages over more traditional step-wise methodologies in terms of step-economy, cost, execution time and waste minimization. ${ }^{[2]}$

Since 2012, our laboratory has pursued the development of new synthetic methodologies based on the use of simple zinc salts as catalysts. ${ }^{[3]}$ In particular, we reported the synthesis of furyl-substituted cyclopropane derivatives from enynones and a variety of alkenes (Scheme 1, A). ${ }^{[4]}$ Computational mechanistic studies on this process supported the participation of a 2-furyl zinc(II) carbene intermediate. According to our DFT calculations, the formation of this key intermediate would involve initial coordination of the enynone to the metal centre and subsequent 5-exo-dig cyclization. ${ }^{[5]}$

Taking into account that the enynone starting materials were prepared by conventional base-promoted Knoevenagel

[a] S. Mata, J. González, Dr. R. Vicente, Dr. Luis A. López Departmento de Química Orgánica e Inorgánica and Instituto Universitario de Química Organometálica "Enrique Moles" Universidad de Oviedo

Julián Clavería 8, 33006-Oviedo (Spain)

E-mail: vicenteruben@uniovi.es; lalg@uniovi.es

Supporting information for this article is given via a link at the end of the document.((Please delete this text if not appropriate)) condensation methodologies and the known ability of zinc chloride to catalyze some of these condensation reactions, ${ }^{[6]}$ we realized that a sequence consisting of zinc-catalyzed Knoevenagel condensation followed by cyclization and final cyclopropanation reaction would represent a convenient multicomponent catalytic approach to the final cyclopropane derivatives. ${ }^{[7-9]}$

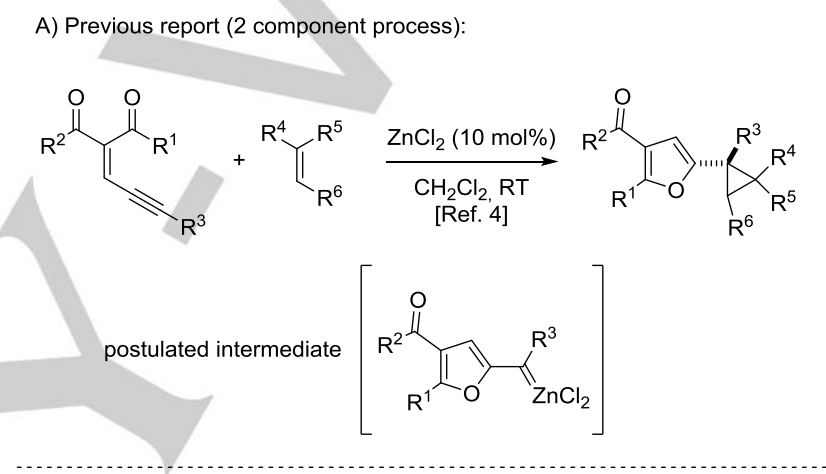

B) This work (3 component process):

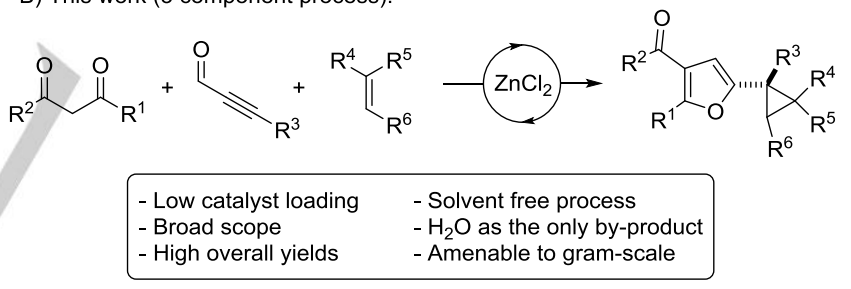

Scheme 1. Zinc-catalyzed approaches to the synthesis of furyl-substituted cyclopropane derivatives: A) Two component approach (reference 4) and B) Multicomponent approach (this work).

Herein, we report the realization of this goal; specifically, we describe the Zn-catalyzed three-component reaction of 1,3dicarbonyl compounds, 2-alkynals and alkenes as a highly efficient method for the preparation of furyl-substituted cyclopropane derivatives (Scheme 1, B). In addition to the inherent advantages associated to the multicomponent reactions in this process affordable $\mathrm{ZnCl}_{2}$ works at very low catalyst loading under mild conditions without the need of organic solvents or additional ligands. Preliminary studies on the reactivity of some of the prepared cyclopropane derivatives are also reported.

The present study has been carried out using 1,3-dicarbonyl compounds 1a-e, 2-alkynals 2a-I, alkenes 3a-n, dienes 3o,p and furan derivatives $3 q-\mathbf{s}$ (Figure 1). 
1,3-Dicarbonylic component

$\mathbf{1 a}\left(R^{1}=R^{2}=\mathrm{Me}\right)$
$\mathbf{1} \mathbf{b}\left(\mathrm{R}^{1}=\mathrm{R}^{2}=\mathrm{Et}\right)$
$\mathbf{1 c}\left(\mathrm{R}^{1}=\mathrm{Me} ; \mathrm{R}^{2}=\mathrm{Ph}\right)$
$\mathbf{1 d}\left(\mathrm{R}^{1}=\mathrm{Me} ; \mathrm{R}^{2}=\mathrm{OEt}\right)$

Figure 1. Starting material used in this work. [a] $\mathrm{PMP}=p-\mathrm{MeOC}_{6} \mathrm{H}_{4}$

\section{Results and Discussion}

Catalyst screening and optimization of reaction conditions. We initially studied the reaction of pentane-2,4-dione (1a), 2octynal (2a), and styrene (3a) as the model substrates. To our delight, we found that heating a mixture of $1 \mathrm{a}$ (1.0 equiv), $2 \mathrm{a}$ (1.1 equiv) and 3a (3.0 equiv) in the presence of $2.0 \mathrm{~mol} \%$ of $\mathrm{ZnCl}_{2}$ at $50{ }^{\circ} \mathrm{C}$ under solvent-free conditions afforded the desired cyclopropane derivative $\mathbf{4 a}$ in $88 \%$ yield after chromatographic purification as a single diastereoisomer (Table 1, entry 1). A control experiment demonstrated that, under otherwise identical conditions, in absence of the $\mathrm{Zn}$ catalyst no reaction was observed (entry 2). Copper and magnesium salts proved to be less efficient catalysts in this transformation (entries 3-5). On the other hand, the use of a larger excess of styrene ( 6 equiv) did not improve the yield of compound $4 \mathbf{a}$ (entry 6 ). The catalyst loading was shown to have an important effect on the yield of this multicomponent process. For instance, while the use of higher catalyst loadings (10 and $20 \mathrm{~mol} \%$ ) resulted in reduced yields (entries 7 and 8 ), virtually the same yield was obtained with 2 and $5 \mathrm{~mol} \%$ (entry 9). Notably, this multicomponent protocol allowed for simultaneous scale-up and lowers catalyst loading with minimal loss in efficiency (entries 10 and 11). For example, for a $10 \mathrm{mmol}$ scale, the catalyst loading can be decreased to as low as $0.02 \mathrm{~mol} \%$. In this case, the isolation after chromatography of $2.45 \mathrm{~g}(79 \%$ yield $)$ of $4 \mathrm{a}$ demonstrated the efficiency $(T O N=3950)$ and scalability of this operationally simple multicomponent process.

Table 1. Zinc-catalyzed multicomponent coupling: Optimization

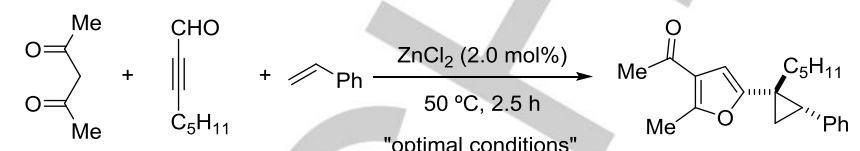

$$
\begin{aligned}
& \begin{array}{llll}
1 \mathbf{1 a} & \mathbf{2 a} & \mathbf{3 a} & \mathbf{4 a}
\end{array} \\
& \text { (1.0 equiv) (1.1 equiv) (3.0 equiv) }
\end{aligned}
$$

\begin{tabular}{|c|c|c|}
\hline entry & change from "optimal conditions" & Yield $(\%)^{[a]}$ \\
\hline 1 & none & 88 \\
\hline 2 & no $\mathrm{ZnCl}_{2}$ & - \\
\hline 3 & $\mathrm{CuCl}(10 \mathrm{~mol} \%)$, instead of $\mathrm{ZnCl}_{2}$ & 11 \\
\hline 4 & $\mathrm{CuCl}_{2}(10 \mathrm{~mol} \%)$, instead of $\mathrm{ZnCl}_{2}$ & 26 \\
\hline 5 & $\mathrm{Mg}\left(\mathrm{ClO}_{4}\right)_{2}(10 \mathrm{~mol} \%)$, instead of $\mathrm{ZnCl}_{2}$ & 10 \\
\hline 6 & 6 equiv of styrene & 81 \\
\hline 7 & $20 \mathrm{~mol} \% \mathrm{ZnCl}_{2}$ & 50 \\
\hline 8 & $10 \mathrm{~mol} \% \mathrm{ZnCl}_{2}$ & 67 \\
\hline 9 & $5.0 \mathrm{~mol} \% \mathrm{ZnCl}_{2}$ & 86 \\
\hline 10 & $0.2 \mathrm{~mol} \% \mathrm{ZnCl}_{2}^{[\mathrm{b}]}$ & 87 \\
\hline 11 & $0.02 \mathrm{~mol} \% \mathrm{ZnCl}_{2}^{[\mathrm{b}]}$ & 79 \\
\hline
\end{tabular}

[a] Yields of isolated products after chromatographic purification. [b] Performed on a $10.0 \mathrm{mmol}$ scale.

Scope of the multicomponent process. With optimal conditions in hand, next we explored the scope of this multicomponent process. First, we extended the process to other common 1,3-dicarbonylic compounds (Scheme 2, A). Thus, heptane-3,5-dione (1b) behaved well and afforded the expected furan derivative $\mathbf{4 b}$ in $69 \%$ isolated yield. The use of an asymmetric diketone, namely 1-phenylbutane-1,3-dione (1c), resulted in the formation of a separable 3:2 mixture of regioisomers $\mathbf{4 c}$ and $4 \mathbf{c}^{\prime}$ in moderate overall yield. A poor stereoselectivity at the Knoevenagel condensation stage might account for the formation of regioisomers $\mathbf{4 c}$ and $4 \mathbf{c}^{\prime}$. In contrast, the use of ethyl 3-oxobutanoate (1d) afforded the corresponding product $\mathbf{4 d}$ in $77 \%$ yield. ${ }^{[10]}$ 1,3-Dimethylbarbituric acid (1e) was found to be an unsuitable substrate since a poor yield of the coupling product was obtained. Regardless of the nature of the dicarbonylic component $\mathbf{1}$, all the reactions involving 2-alkynal 2a and styrene (3a) furnished a single stereoisomer, that is in accordance with the sterochemical outcome observed in the two component version. 


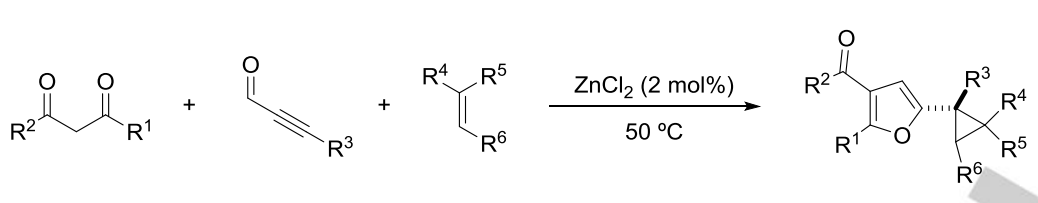

1

3

4

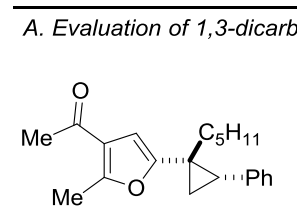

$4 a(88 \%$, d.r. $>20: 1)$

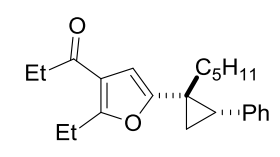

4b $(69 \%$, d.r. $>20: 1)$

$$
\text { (Me)Ph }
$$

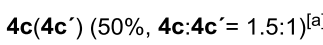

(in both cases d.r. $>20: 1$ )

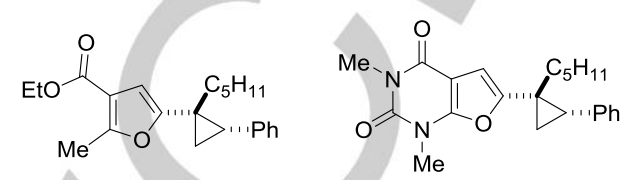

4d (77\%, d.r. > 20:1)

4 e $(11 \%$, d.r. $>20: 1)$

B. Evaluation of 2-alkynal component.<smiles>CC(=O)c1cc([C@]2(CCc3ccccc3)C[C@H]2c2ccccc2)oc1C</smiles>

$4 f(83 \%$, d.r. $>20: 1)$<smiles>CC(=O)c1cc(C2([13CH3])C[C@H]2c2ccccc2)oc1C</smiles><smiles>CCCCOC1C[C@@]1(c1cc(C(C)=O)c(C)o1)C1CCCC1</smiles>

$4 \mathbf{g}(44 \% \text {, d.r. }>20: 1)^{[\mathrm{b}, \mathrm{c}]}$<smiles>CC(=O)c1cc([C@]2(C3CC3)C[C@H]2c2ccccc2)oc1C</smiles>

4h $(68 \%$, d.r. $>20: 1)$<smiles>CCCCCCc1cc(C(C)=O)c(C)o1</smiles>

$4 \mathbf{i}(31 \%$, d.r. $>20: 1)$<smiles>CC(=O)c1cc([C@]2(CCO[BH2-]C(C)(C)C)C[C@H]2c2ccccc2)oc1C</smiles>

4j $(63 \%$, d.r. $>20: 1)$

4k $(\mathrm{R}=\mathrm{Me} ; 75 \%$, d.r. $>20: 1)$ 4I (R = Et; $41 \%$, d.r. $>20: 1)^{[d]}$

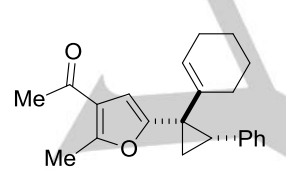

$4 \mathrm{~m}(31 \%$, d.r. $=3: 1)$

C. Evaluation of alkene component.<smiles>CC(=O)c1cc([C@]2([13CH3])C[C@H]2Br)oc1C</smiles>

4q $\left(\mathrm{Ar}=4-\mathrm{MeC}_{6} \mathrm{H}_{4}, 70 \%\right.$, d.r. $\left.>20: 1\right)$ $4 \mathrm{r}\left(\mathrm{Ar}=4-\mathrm{MeOC}_{6} \mathrm{H}_{4}, 72 \%\right.$, d.r. $\left.>20: 1\right)$ 4s $\left(X=4-\mathrm{NO}_{2} \mathrm{C}_{6} \mathrm{H}_{4}, 41 \%\right.$, d.r. $\left.>20: 1\right)$ 4t $\left(\mathrm{R}^{3}=\mathrm{TMS} ; \mathrm{R}=n-\mathrm{Bu}, 36 \%\right.$, d.r. $\left.>20: 1\right)$

$4 \mathbf{u}\left(\mathrm{R}^{3}=\mathrm{C}_{5} \mathrm{H}_{11} ; \mathrm{R}=\mathrm{TMS}, 65 \%\right.$, d.r. $\left.=3: 1\right)$ $4 \mathbf{v}\left(R^{3}=R=T M S, 54 \% \text {, d.r. }>20: 1\right)^{[d]}$<smiles>[R]C(=O)c1cc(C2([R])CC2(c2ccccc2)c2ccccc2)oc1[R]</smiles>

$4 \mathbf{w}\left(\mathrm{R}^{1}=\mathrm{R}^{2}=\mathrm{Me} ; \mathrm{R}^{3}=\mathrm{C}_{5} \mathrm{H}_{11}, 85 \%\right)$ $4 x\left(R^{1}=R^{2}=M e ; R^{3}=P h, 70 \%\right)$ $4 y\left(R^{1}=R^{2}=E t ; R^{3}=C_{5} H_{11}, 83 \%\right)$ $4 z\left(R^{1}=\right.$ Me; $R^{2}=$ OEt; $\left.R^{3}=C_{5} H_{11}, 70 \%\right)$ 4aa $\left(R^{1}=R^{2}=M e ; R^{3}=4-M^{2} O_{6} H_{4}, 54 \%\right)^{[e]}$ 4ab $\left(R^{1}=M e ; R^{2}=\right.$ OEt; $\left.R^{3}=4-M_{e O C} H_{4}, 42 \%\right)$

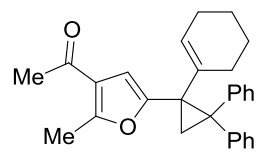

4 ac $(35 \%)$

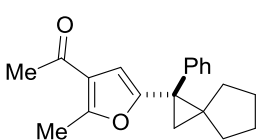

4ad $(63 \%)$<smiles>CCCCCC1(c2cc(C(C)=O)c(C)o2)CC12CCCC2C(C)(C)C</smiles>

4ae $(61 \%$, d.r. $=1.0: 1.0)$

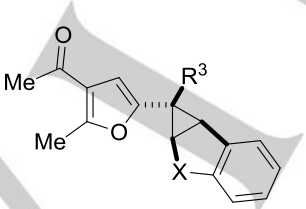

4af $\left(\mathrm{R}^{3}=\mathrm{C}_{5} \mathrm{H}_{11}, \mathrm{X}=\mathrm{CH}_{2} 86 \% \text {, d.r. }>20: 1\right)^{[\mathrm{f}]}$ 4ag $\left(R^{3}=P h, X=C_{2}, 64 \%\right.$, d.r. > 20:1) 4ah $\left(R^{3}=P h, X=O 35 \%\right.$, d.r. $\left.>20: 1\right)$<smiles></smiles>

4ai $\left(\mathrm{R}^{3}=\mathrm{Ph}, \mathrm{n}=1,45 \%\right.$, d.r. $\left.>20: 1\right)$

4aj $\left(\mathrm{R}^{3}=\mathrm{C}_{5} \mathrm{H}_{11}, \mathrm{n}=2,49 \%\right.$, d.r. $\left.=3: 1\right)$<smiles>CCOCCCCCC#CC1C[C@@]1(c1ccccc1)c1ccccc1C(C)=O</smiles>

4ak $(63 \%$, d.r. $>20: 1)$

Scheme 2. Zn-catalyzed three-component reaction of 1,3-dicarbonyl compounds 1, 2-alkynals 2 and alkenes 3: Scope (Values are referred to isolated yields. d.r. was determined by ${ }^{1} \mathrm{H}$ NMR). [a] . Two separable regioisomers formed (4c and $\mathbf{4} \mathbf{c}^{\prime}$ in $30 \%$ and $20 \%$ yield, respectively). [b] With 10 mol\% of catalyst. [c] Along with a 2-vinylfuran side-product $\mathbf{4 g}^{\prime}\left(\mathbf{4 g}: \mathbf{4} \mathbf{g}^{\prime}=7.1: 1\right)$. [d] Performed at $120 \stackrel{\circ}{ } \mathrm{C}$ using microwave heating. [e] With 5 mol\% of catalyst. [f] The yield was $63 \%$ with 0.02 $\mathrm{mol} \%$ of $\mathrm{ZnCl}_{2}$ 
Next, we examined the scope with respect to the alkynal component (Scheme 2, B). A broad set of substituents at the alkyne terminus turned out to be compatible, including alkyl, cycloalkyl, alkenyl and aryl groups. Significantly, in the reaction of enynone $2 \mathrm{c}\left(\mathrm{R}^{3}=\right.$ cyclopentyl) along with the expected cyclopropane derivative $\mathbf{4 g}$ a 2 -vinylfuran side-product $\left(\mathbf{4} \mathbf{g}^{\prime}\right)$ was also formed. ${ }^{[11]}$ Once again, in complete agreement with the sterochemical outcome observed in the two-component process the stereoselectivity of the process was highly dependent on the nature of the substituent on the alkynal. While the reaction with alkynals bearing alkyl groups proceeded in general with complete stereoselectivity, the use of those with aromatic groups led to mixtures of diastereoisomers. Even alkynals $\mathbf{2 g}$ and $\mathbf{2 h}$ bearing trialkylsilyl groups were also tolerated without any detrimental effect on the chemical yield of the multicomponent process. In this case the reaction took place with complete stereoselectivity.

Then, a number of olefinic partners were also evaluated (Scheme 3, C). First, we investigated the effect on the reaction outcome of the electronic nature of substituents on the aryl ring in styrene derivatives. Thus, we found that under the standard reaction conditions electron-rich styrenes $\mathbf{3 b}$ and $\mathbf{3 c}$ were effective reactants affording the cyclopropane derivatives $\mathbf{4 q}, \mathbf{r}$ in good yields (70 and $72 \%$, respectively). In contrast, 4nitrostyrene $(\mathbf{3 d})$ led to the corresponding cyclopropane $4 \mathbf{s}$ in diminished yield $(41 \%)$. Once again, regardless of the nature of the substituted styrene used, in all the reactions involving alkynal 2a the final adduct was isolated as a single stereoisomer The reaction with alkyl-monosubstituted alkenes resulted far more sluggish. Even so, 1-hexene (3e) and allyltrimehylsilane (3f) delivered the expected products $4 \mathbf{t}-\mathbf{v}$ in moderate yields.

1,1-Disubstituted alkenes are also able to participate in this multicomponent process. Indeed, reactions of 1,1diphenylethene $(\mathbf{3 g})$ proceeded smoothly to deliver cyclopropane derivatives $\mathbf{4 x - 4 a c}$ in general in good yields. Likewise, methylenecyclopentane (3h) gave cyclopropane $4 \mathrm{ad}$ in $63 \%$ yield. Interestingly, the reaction of $\beta$-pinene $(3 \mathbf{i})$ afforded the cyclopropane 4ae in moderate yield as a mixture of stereoisomers. Notably, no products resulting from rearrangements were observed in this reaction. Indene $(\mathbf{3} \mathbf{j})$ and benzofuran (3k) were also suitable alkenes affording cyclopropanes 4af-ah as single isomers in good yields. Enolether derivatives $\mathbf{3 I}$ and $\mathbf{3} \mathbf{m}$ also underwent this transformation giving rise to cyclopropane derivatives 4ai,aj in moderate yields and selectivity. Finally, the reaction with enyne 3h took place with complete chemoselectivity with exclusive participation of the olefinic moiety.

Our attention then turned towards determining whether diene derivatives would be suitable substrates in this zinc-catalyzed multicomponent process. To this end, first we reacted pentane2,4-dione (1a), 2-octynal (2a), 2,3-dimethyl-1,3-butadiene (30), and $\mathrm{ZnCl}_{2}(2 \mathrm{~mol} \%)$. Stirring for $12 \mathrm{~h}$ at room termperature resulted in the formation of an almost $1: 1$ mixture of vinylcyclopropane $\mathbf{5 a}$ and cycloheptafuran $\mathbf{6 a}$ in moderate yield (Scheme 3). ${ }^{[12]}$ Similarly, 3-phenylpropiolaldehyde (2j) furnished a $1: 2$ mixture of $\mathbf{5} \mathbf{b}$ and $\mathbf{6} \mathbf{b}$.

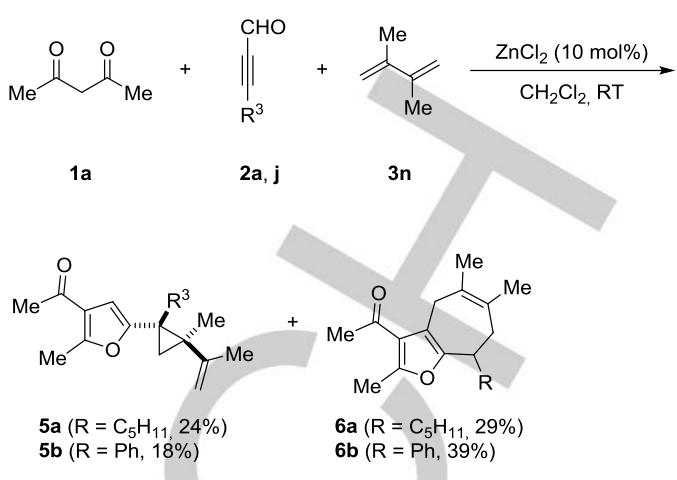

Scheme 3. Zn-catalyzed three-component reaction of pentane-2,4-dione (1a), alkynals $\mathbf{2 a}$,j and 2,3-dimethyl-1,3-butadiene (3n).

The use of 1,3-cyclopentadiene (3p) was also explored (Scheme 4). Thus, under essentially identical reaction conditions (RT, 2 mol\% $\mathrm{ZnCl}_{2}$ ), pentane-2,4-dione (1a), 3-phenylpropiolaldehyde (2j), and cyclopentadiene (3p) afforded exclusively the cyclopropane derivative $\mathbf{7}$ as a single isomer in moderate isolated yield (61\%).

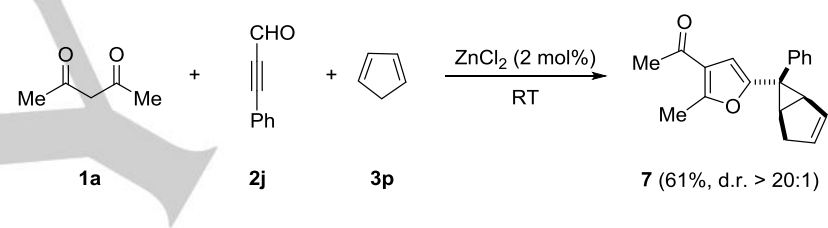

Scheme 4. Zn-catalyzed three-component reaction of pentane-2,4-dione (1a), 3-phenylpropiolaldehyde (2j), and cyclopentadiene (3p).

Finally, we examined the reactivity towards furan derivatives (Scheme 5). In this process we did not obtain cyclopropane derivatives; instead, diene derivatives resulting from a ringopening process were isolated as mixture of isomers in moderate yields. ${ }^{[13]}$ In this case, the reaction of pentane-2,4dione (1a), 3-phenylpropiolaldehyde (2j) and furan (3q) in the presence of $2 \mathrm{~mol} \%$ of $\mathrm{ZnCl}_{2}$ proceeded smoothly at room temperature to give the furyl substituted diene $\mathbf{8 a}$ in moderate yield and selectivity along with side-product $8 \mathbf{a}^{\prime}$ resulting from the formal insertion of the zinc carbene intermediate into the C2$\mathrm{H}$ bond of the furan. The reaction of pentane-2,4-dione (1a), 2octynal (2a) and 2-methylfuran (3r) under similar conditions proceeded with complete regioselectivity providing dienic ketone $\mathbf{8 b}$ in moderate yield. In a similar way, 2,5-dimethylfuran provided the diene derivative $8 \mathrm{c}$ ( $59 \%$ yield). It should be noted that, although diene derivatives $\mathbf{8 b}$ and $\mathbf{8 c}$ are obtained as mixtures of stereoisomers, they can be quantitatively transformed into the most stable $(E, E)$-isomer by treatment of the reaction crudes with a catalytic amount of iodine. ${ }^{[14,15]}$ 


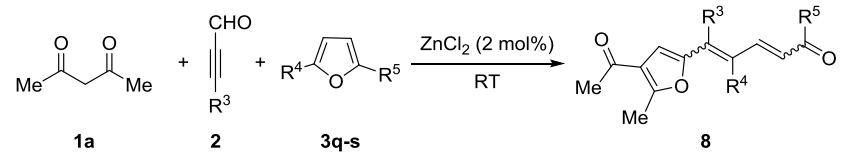

1a

$8 \mathbf{a}(60 \%$, d.r. $=4.2: 2: 1: 1)$ $\mathbf{8 b}(51 \%)^{[a]}$ $8 \mathrm{c}(59 \%)^{[a]}$

Identified side-products

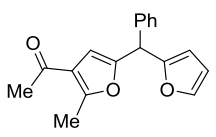

$8 \mathbf{a}^{\prime}(8 \%$, along with $8 \mathbf{a})$

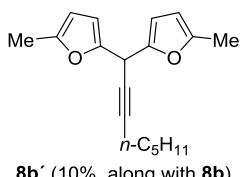

Scheme 5. Zn-catalyzed three-component reaction of pentane-2,4-dione (1a) alkynals $2 a$,j and furan derivatives $3 q\left(R^{4}=R^{5}=H\right), 3 r\left(R^{4}=H, R^{5}=M e\right)$, and 3s $\left(\mathrm{R}^{4}=\mathrm{R}^{5}=\mathrm{Me}\right)$. [a] Isolated as $(E, E)$-isomer after treating the reaction crude with a catalytic amount of iodine.

Rearrangement of vinylcyclopropanes $4 \mathrm{ac}$ and $5 \mathrm{a}$. The thermal and metal-promoted rearrangements of vinylcyclopropane derivatives have become a well-established methodology for the synthesis of substituted cyclopentenes, ${ }^{[16]}$ which are important structural motifs of natural products and pharmaceuticals. We therefore set out to investigate the viability of a rearrangement of compounds $4 \mathbf{a c}$ and $5 \mathbf{a}$ featuring a vinylcyclopropane structure under zinc catalysis. Pleasingly, we found that heating a solution of the corresponding vinylcyclopropane in 1,2-dichloroethane (DCE) (50 $\mathrm{C}$ for $4 \mathrm{ac}$; $70{ }^{\circ} \mathrm{C}$ for $5 \mathrm{a}$ ) in the presence of $25 \mathrm{~mol} \%$ of $\mathrm{ZnCl}_{2}$ led to the rearranged products 9 and 10 in 78 and $58 \%$ yield, respectively (Scheme 6). Remarkably, this metal-catalyzed rearrangement took place with complete regioselectivity. The carbon-carbon bond that is broken in this process is that one between the more substituted carbon atoms of the cyclopropane ring.

Although further experimentation is yet required to delineate the actual role of the zinc salt in this rearrangement process, control experiments performed in the absence of $\mathrm{ZnCl}_{2}$ demonstrated that it has a notable influence on the reaction outcome as low conversions were achieved in the absence of the zinc salt. ${ }^{[17]}$

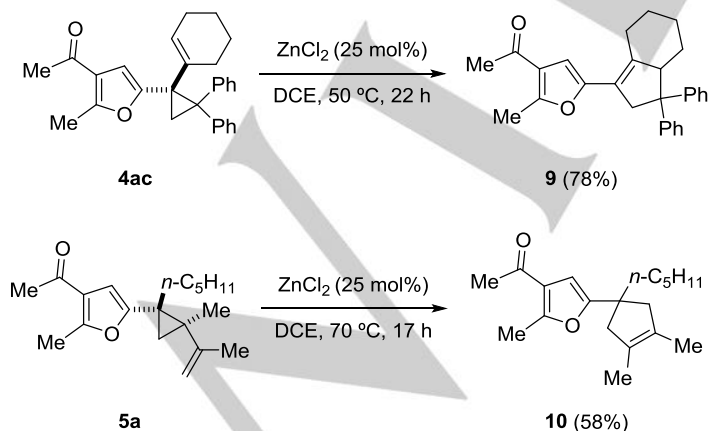

Zinc-catalyzed aerobic oxidation of cyclopropanes 4: synthesis of 1,2-dioxolane derivatives 11. Having developed a convenient method for the preparation of furylcyclopropane derivatives we then turned our interest in seeking some synthetic applications thereof. Owing to their interesting biological activities, mainly as antimalarial reagents, first we investigated the transformation of cyclopropane derivatives 4 into cyclic peroxide derivatives, namely 1,2-dioxolanes. ${ }^{[18]}$ Although the oxidation of some cyclopropane derivatives by oxygen has been reported, ${ }^{[19]}$ to the best of our knowledge the use of zinc as catalyst in this transformation is unprecedented. In this regard, we were pleased to find that when a mixture of cyclopropane $\mathbf{4 w}$ and 0.5 equiv of $\mathrm{ZnCl}_{2}$ was stirred in DCE at $80{ }^{\circ} \mathrm{C}$ under air, 1,2-dioxolane 11a was obtained in $41 \%$ yield after 45 hours. After a brief catalyst screening and optimization of reaction conditions, we found that the use of $1 \mathrm{~atm}$ of oxygen in dichloroethane at $50{ }^{\circ} \mathrm{C}$ in the presence of $50 \mathrm{~mol} \%$ of $\mathrm{ZnCl}_{2}$ provided the desired product 11a in an excellent yield after chromatographic purification (89\%).

The reaction was then extended to other cyclopropane derivatives delivering the 1,2-dioxolane derivatives $\mathbf{1 1 b}$-11f in isolated yields ranging from moderate to good (Scheme 7). The process tolerated both alkyl and aryl groups at the C-1 position of the cyclopropane. Unfortunately, only 2,2-diphenyl substituted cyclopropane derivatives were competent substrates in this oxidation. ${ }^{[20]}$

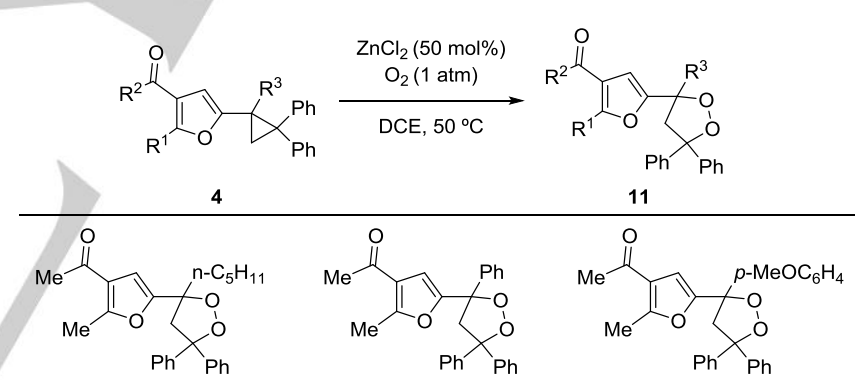

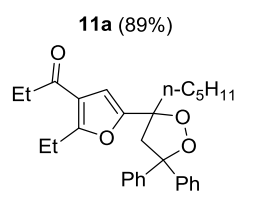

11d $(80 \%)$
$11 \mathrm{~b}(63 \%)$<smiles>CCOC(=O)c1cc(C2(c3ccccc3)CC(c3ccccc3)(c3ccccc3)O2)oc1C</smiles>

$11 \mathrm{e}(67 \%)$ 11c $(78 \%)$<smiles>CCOC(=O)c1cc(C2(c3ccccc3)COC(c3ccccc3)(c3ccccc3)O2)oc1C</smiles>

$11 f(62 \%)$
Scheme 7. Synthesis of 1,2-dioxolane derivatives 11 from diphenyl substituted cyclopropanes 3 .

The structure of compounds $\mathbf{1 1}$ was ascertained by NMR methods and mass spectrometry. Moreover, a single-crystal analysis of compound $\mathbf{1 1 b}$ unambiguously confirmed the proposed structure (Figure 2). ${ }^{[21]}$ 


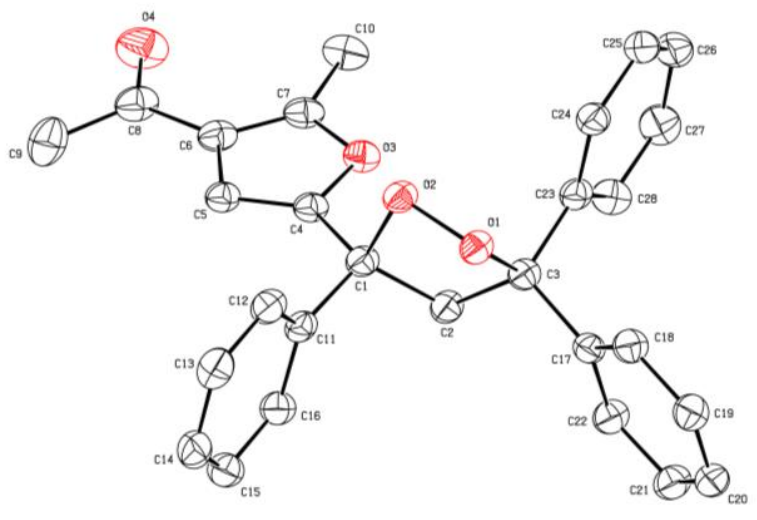

Figure 2. ORTEP view of compound $\mathbf{1 1 b}$ (ellipsoids at $30 \%$ probability level)

Finally, we wondered whether the synthesis of 1,2-dioxolane derivatives could be accomplished in a multicomponent process from 1,3-dicarbonyl compounds $\mathbf{1}$, alkynals 2, and alkenes $\mathbf{3}$ without isolating the corresponding cyclopropane. Pleasingly, we found that heating a solution of pentane-2,4-dione (1a), 2octynal (2a), 1,1-diphenylethene $(\mathbf{3 g})$ in dichloroethane at $50 \stackrel{\circ}{\circ} \mathrm{C}$ in the presence of $50 \mathrm{~mol} \%$ of $\mathrm{ZnCl}_{2}$ under an oxygen atmosphere provided 1,2-dioxolane 11a in $67 \%$ yield after chromatographic purification (Scheme 8). In a similar vein, heptane-3,5-dione (1b) gave 1,2-dioxolane 11d in 64\% yield.

$$
\mathrm{O}==_{\mathrm{R}}^{\mathrm{R}}+\|_{n-\mathrm{C}_{5} \mathrm{H}_{11}}^{\mathrm{CHO}}+\prod^{\mathrm{Ph}} \prod^{\mathrm{Ph}} \stackrel{\begin{array}{c}
\mathrm{ZnCl}_{2}(50 \mathrm{~mol} \%) \\
\mathrm{O}_{2}(1 \mathrm{~atm})
\end{array}}{\mathrm{DCE}, 50^{\circ} \mathrm{C}}
$$

$1 a(R=M e) \quad 2 a$ $1 \mathbf{b}(\mathrm{R}=\mathrm{Et})$
Scheme 8. Four-component approach to 1,2-dioxolane derivatives 11

\section{Conclusions}

We have described an efficient synthesis of furyl-substituted cyclopropane derivatives through a zinc-catalyzed threecomponent coupling of 1,3-dicarbonyl compounds, alkynals and alkenes. This coupling process, which seemingly proceeds through a 2-furyl zinc(II) carbene intermediate, merges Knoevenagel condensation, cyclization and cyclopropanation into a multicomponent procedure. General features of this operationally simple multicomponent protocol are: 1) the availability and low cost of the required starting materials and catalyst, 2) a great scope of all the components, 3) its efficiency (even working at catalyst loading as low as $0.02 \mathrm{~mol} \%$ ), and 4) its suitability for multi-gram scale-up. Selected cyclopropane derivatives proved to be suitable starting materials for further transformations. Specifically, the ability of $\mathrm{ZnCl}_{2}$ to promote the vinylcyclopropane-cyclopentene rearrangement has been demonstrated for the first time. On the other hand, the synthesis of 1,2-dioxolane derivatives through a zinc-promoted aerobic oxidation of cyclopropane derivatives has been also developed. A four-component process yielding these cyclic peroxide derivatives has been also realized.

\section{Experimental Section}

Typical Procedure for the $\mathrm{Zn}$-catalyzed Three-Component Coupling: Synthesis of cyclopropane 4a. To a mixture of 2,4-pentanedione (1a $30.0 \mathrm{mg}, 0.30 \mathrm{mmol}$ ), oct-2-ynal (2a, $41.0 \mathrm{mg}, 0.33 \mathrm{mmol}$ ) and styrene (3a, $93.7 \mathrm{mg}, 0.90 \mathrm{mmol}), \mathrm{ZnCl}_{2}(0.85 \mathrm{mg}, 2.0 \mathrm{~mol} \%)$ was added at ambient temperature under inert atmosphere. The Schlenk flask was sealed with a septum and placed in a pre-heated oil bath at $50 \stackrel{\circ}{\circ} \mathrm{C}$ and stirred for $5 \mathrm{~h}$ at this temperature until disappearance of the starting material (checked by TLC analysis). Excess of the styrene was removed under vacuum. The resulting residue was purified by flash column chromatography $\left(\mathrm{SiO}_{2}\right.$, hexane/EtOAc $\left.=10: 1\right)$ to afforded $\mathbf{4 a}(82 \mathrm{mg}$, $88 \%$; d.r. $>20: 1$ ) as a pale yellow oil.

Typical Procedure for the Zn-catalyzed Aerobic Oxidation of Cyclopropane Derivatives: Synthesis of 1,2-Dioxolane Derivative 11a. To a solution of cyclopropane $4 \mathbf{w}(56 \mathrm{mg}, 0.15 \mathrm{mmol})$ in 1,2dichloroethane (1.5 mL, $0.10 \mathrm{M}), \mathrm{ZnCl}_{2}(10 \mathrm{mg}, 50 \mathrm{~mol} \%$ ) was added at ambient temperature under oxygen atmosphere. The Schlenk flask was sealed with a septum and placed in a pre-heated oil bath at $50{ }^{\circ} \mathrm{C}$ and stirred for $15 \mathrm{~h}$ at this temperature until disappearance of the starting material (checked by TLC analysis). After elimination of the solvent, purification by flash column chromatography $\left(\mathrm{SiO}_{2}\right.$, hexane/EtOAc $=10: 1$ yielded 11 a ( $52 \mathrm{mg}, 89 \%$ ) as a colourless oil.

\section{Acknowledgements}

Financial support from Ministerio de Economía y Competitividad (MINECO) and Principado de Asturias (grants no. CTQ201341511-P, GRUPIN14-013) is gratefully acknowledged. R. V. is a Ramón y Cajal fellow. S. M. thanks the Principado de Asturias for a predoctoral grant (Severo Ochoa Program). We thank Prof. J. M. González for interesting discussions and Dr. J. Borge for his assistance in the collection of X-ray data.

Keywords: cyclopropane $\cdot$ dioxolanes $\bullet$ furan derivatives $•$ multicomponent reactions $\cdot$ zinc

[1] Selected reviews: a) Catalysis without precious metals (Ed.: R. B. Bullock), Wiley-VCH, Weinhem, 2010; b) M. S. Holzwarth, B. Plietker, ChemSusChem. 2013, 5, 1650. See also the special issue Earth Abundant Metals in Homogeneous Catalysis (Eds.: P. Chirik, R. Morris), Acc. Chem. Res. 2015, 48, 2576-2621.

[2] Selected reviews on multicomponent reactions: a) Multicomponent Reactions (Eds.: J. Zhu, H. Bienaymé), Wiley-VCH, Weinhem (Germany), 2005; b) Domino Reactions: Concepts for Efficient Organic Synthesis (Ed.: L. F. Tietze), Wiley-VCH, Weinhem (Germany), 2004; c) A. Dömling, W. Wang, K. Wang, Chem. Rev. 2012, 112, 3083; d) P. Slobbe, E. Ruijter, R. V. A. Orru, MedChemComm. 2013, 3, 1189; e) Science of Synthesis: Multicomponent Reactions (Ed.: T. J. J. Muller), Georg Thieme Verlag KG, Stuttgart, 2014.

[3] Recent revisions on zinc catalysis: a) S. Enthaler, X.-F. Wu (Eds.) in Zinc Catalysis, Applications in Organic Synthesis, Wiley- $\mathrm{VCH}$, 
Weinheim, 2015; b) M. J. González, L. A. López, R. Vicente, Tetrahedron Lett. 2015, 56, 1600; c) S. Enthaler, ACS Catal. 2013, 3, 150; d) X.-F. Wu, H. Neumann, Adv. Synth. Catal. 2012, 354, 3141; e) X.-F. Wu, Chem. Asian J. 2012, 7, 2502.

[4] R. Vicente, J. González, L. Riesgo, J. González, L. A. López, Angew. Chem. 2012, 124, 8187; Angew. Chem. Int. Ed. 2012, 51, 8063. See also: S. Mata, L. A. López, R. Vicente, Synlett 2015, 26, 2685.

[5] For further contributions involving trapping of the postulated zinc carbene intermediate, see: a) J. González, L. A. López, R. Vicente Chem. Commun. 2014, 50, 8536; b) M. J. González, L. A. López, R Vicente, Org. Lett. 2014, 16, 5780.

[6] P. S. Rao, R. V. Venkataratnam, Tetrahedron Lett. 1991, 32, 5821.

[7] For selected reviews on the synthetic relevance of cyclopropane derivatives, see: a) C. J. Thibodeaux, W.-C. Chang, H.-W. Liu, Chem. Rev. 2012, 112, 1681; b) M.-N. Roy, V. N. G, Lindsay, A. B. Charette, Stereoselective Synthesis: Reactions of Carbon-Carbon Double Bonds Vol 1. (Science of Synthesis) (Ed. J. G. de Vries), Thieme, Stuttgart, 2011, pp. 731-817; c) C. A. Carson, M. A. Kerr, Chem. Soc. Rev. 2009, 38, 3051; d) F. Brackmann, A. de Meijere, Chem. Rev. 2007, 107, 4493; e) H.-U. Reissig, R. Zimmer, Chem. Rev. 2003, 103, 1151; f) H. Lebel, J.-F. Marcoux, C. Molinaro, A. B. Charette, Chem. Rev. 2003, $103,977$.

[8] The development of zinc-catalyzed cyclopropanation reactions represents a significant goal. For isolated examples of zinc-catalyzed synthesis of cyclopropane derivatives, see: a) S. R. Goudreau, A. B. Charette, J. Am. Chem. Soc. 2009, 131, 15633; b) É. Lévesque, S. R Goudreau, A. B. Charette, Org. Lett. 2014, 16, 1490; c) M. J. González, J. González, L. A. López, R. Vicente, Angew. Chem. 2015, 127, 12307; Angew. Chem. Int. Ed. 2015, 54, 12139.

[9] For a multicomponent process involving Knoevenagel condensation, cyclization and carbene Si-H insertion, see: S. Mata, L. A. López, R Vicente, Chem. Eur. J. 2015, 21, 8998.

[10] The yield obtained in this reaction could be rationalized in terms of isomerization of the enynone or retro-Knoevenagel condensation. In fact, the condensation of ethyl 3-oxobutanoate (1d) with alkynal 2a under standard Knoevenagel conditions led to a 1.2:1 Z/E mixture of the corresponding adducts, For a similar outcome, see reference 9.

[11] This side-product would arise from a competitive 1,2-hydride shift at the carbene stage. 2-Vinylfuran $\mathbf{4} \mathbf{g}$ ' was obtained in $60 \%$ yield when mixing 1a and $\mathbf{2 c}$ with $\mathrm{ZnCl}_{2}$ in the absence of the alkene.

[12] Very likely cycloheptafuran derivatives $6 \mathbf{a}$ and $\mathbf{6 b}$ arise from the cisconfigurated cyclopropane derivatives, that can further evolve under the reaction conditions. The zinc-catalyzed [4+3] cycloaddition of enynones with electron-rich dienes to give cycloheptafuran derivatives related to compounds 6 has been recently reported: B. Song, L.-H. Li, X.-R. Song, Y.-F. Qiu, M.-J. Zhong, P.-X- Zhou, Y.-M. Liang, Chem. Eur. J. 2014, 20, 5910 .

[13] A similar ring-opening process has been reported in the reaction of furan other metalcarbene complexes. For selected examples, see: a) $\mathrm{K}$. Miki, M. Fujita, S. Uemura, K. Ohe, Org. Lett. 2006, 8, 1741; b) A. Caballero, M. M. Díaz-Requejo, S. Trofimenko, T. R. Belderrain, P. J. Pérez, J. Org. Chem. 2005, 70, 6101; c)

[14] The reaction of diene $8 \mathbf{a}$ with iodine afforded a complex mixture of products.

[15] For some applications of this iodine-catalyzed isomerization reaction, see: E. Wenkert, M. Guo, R. Lavilla, B. Porter, K. Ramachandran, J.-H. Sheu, J. Org. Chem. 1990, 55, 6203.

[16] a) For a review on thermal rearrangements of vinylcyclopropanes, see: J. E. Baldwin, Chem. Rev. 2003, 103, 1197. B) For a review on metal promoted vinylcyclopropane-cyclopentene rearrangements, see: S. C. Wang, D. F. Tantillo, J. Organomet. Chem. 2006, 691, 4386. C) For a review on the discovery and synthetic applications of the vinylcyclopropane-cyclopentene rearrangement, see: T. Hudlicky, J. W. Reed, Angew. Chem. 2010, 122, 4982; Angew. Chem. Int. Ed. 2010, 49, 4864.

[17] For example, heating vinylcyclopropane $5 \mathbf{a}$ in DCE at $70 \stackrel{\circ}{\circ} \mathrm{C}$ for 17 hours resulted in a $3: 1$ mixture of the starting cyclopropane and the rearranged product 10 .

[18] For a recent review on the synthesis of five- and six-membered cyclic organic peroxides, see: A. O. Terent'ev, D. A. Borisov, V. A. Vil', V. M. Dembitsky, Beilstein J. Org. Chem. 2014, 10, 34.

[19] For selected recent examples, see: a) F. Nuter, A. K. D. Dimé, C. Chen, L. Bounaadja, E. Mouray, I. Florent, Y. Six, O. Buriez, A. Marinetti, A Voituriez, Chem. Eur. J. 2015, 21, 5584; b) Z. Lu, J. D. Parrish, T. P. Yoon, Tetrahedron, 2014, 70, 4270; c) X.-Y. Sun, X.-Y. Tian, Z.-W. Li, X.-S. Peng, H. N. C. Wong, Chem. Eur. J. 2011, 17, 5874.

[20] For example, the reaction of cyclopropane $\mathbf{4 a}$ under otherwise simila reaction conditions afforded a complex mixture of products. On the other hand, no reaction was observed when cyclopropane 4ad was subjected to the standard reaction conditions.

[21] CCDC-1451935 (11b) contains the supplementary crystallographic data for this paper. These data can be obtained free of charge from The Cambridge Crystallographic Data Centre via www.ccdc.cam.ac.uk/data\%5Frequest/cif. 


\section{FULL PAPER}

Simplicity! A operationally simple protocol for the synthesis of furylsubstituted cyclopropane derivatives from readily available substrates (1,3-dicarbonyl compounds, alkynals and alkenes) is reported. Affordable $\mathrm{ZnCl}_{2}$ serves as an efficient catalyst for this multicomponent process. For some combinations of reagents, the synthesis of dioxolane derivatives through a four component process involving incorporation of oxygen has been also developed.

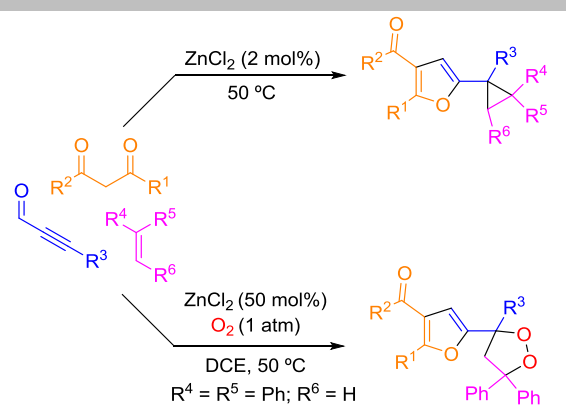

Sergio Mata, Jesús González, Rubén Vicente, * Luis A. López*

Page No. - Page No.

Zinc-Catalyzed Multicomponent Reactions: Easy Access to FurylSubstituted Cyclopropane and 1,2Dioxolane Derivatives 